\title{
Online education in Russia: status and development trends
}

\author{
Oksana Pirogova ${ }^{1, *}$, Nataliia Temnova $^{2}$, and Elena Markova ${ }^{3}$ \\ ${ }^{1}$ Peter the Great St. Petersburg Polytechnic University, 195251, 29 Polytechnicheskaya str., St. \\ Petersburg, Russia \\ ${ }^{2}$ Herzen State Pedagogical University of Russia, 191186, 48 Moika Embankment, St. Petersburg, \\ Russia \\ ${ }^{3}$ Ivanovo State University, 153025, 39 Ermaka str., Ivanovo, Russia
}

\begin{abstract}
The online education market is showing growth and strengthening of its position as a business area not only in Russia, but also all over the world, increasing the industry growth rate up to $20 \%$ per year. The main and significant jump occurred because of the active transition to online due to the covid-19 quarantine restrictions. The purpose of this work is to study the online education system in Russia and determine the prospects for the development of this industry. The tasks of the research include comparing online education with the offline sphere, analyzing popular categories in online education and forecasting the dynamics of market development, taking into account the influence of the revenue of online education companies. The main methods used in the work: data analysis and comparison. Based on the results of the study, the main conclusions were obtained: every year there is an increase in investments in the field of online education, large companies buy promising projects. Based on the correlation-regression model of the dependence of the period under study on the volume of the online education market in Russia, a forecast for the coming years has been made. The most popular areas of study: foreign languages, IT and marketing. The year 2020 allowed the industry to increase its performance more than it was predicted, and by 2021 , the revenue is expected to increase to 73 billion rubles.
\end{abstract}

\section{Introduction}

Nowadays, all spheres of activity, one way or another, are trying to master online opportunities for providing services. The pandemic has had a huge impact on the Russian online education sector (EdTech industry) and is currently growing at a record pace, due to the residual impact of the pandemic and the transition to online.

Online learning is the acquisition of knowledge and skills using a computer or other devices connected to the Internet in the "here and now" mode. This learning format is also called "e-learning", and it is considered a logical continuation of distance [1].

\footnotetext{
* Corresponding author: kafedra17@rambler.ru
} 
Online education is divided into four subgroups, now it is mainly e-learning that is developing, with the help of various courses, which is associated with the mobile learning group. Figure 1 shows the types of online learning [2].

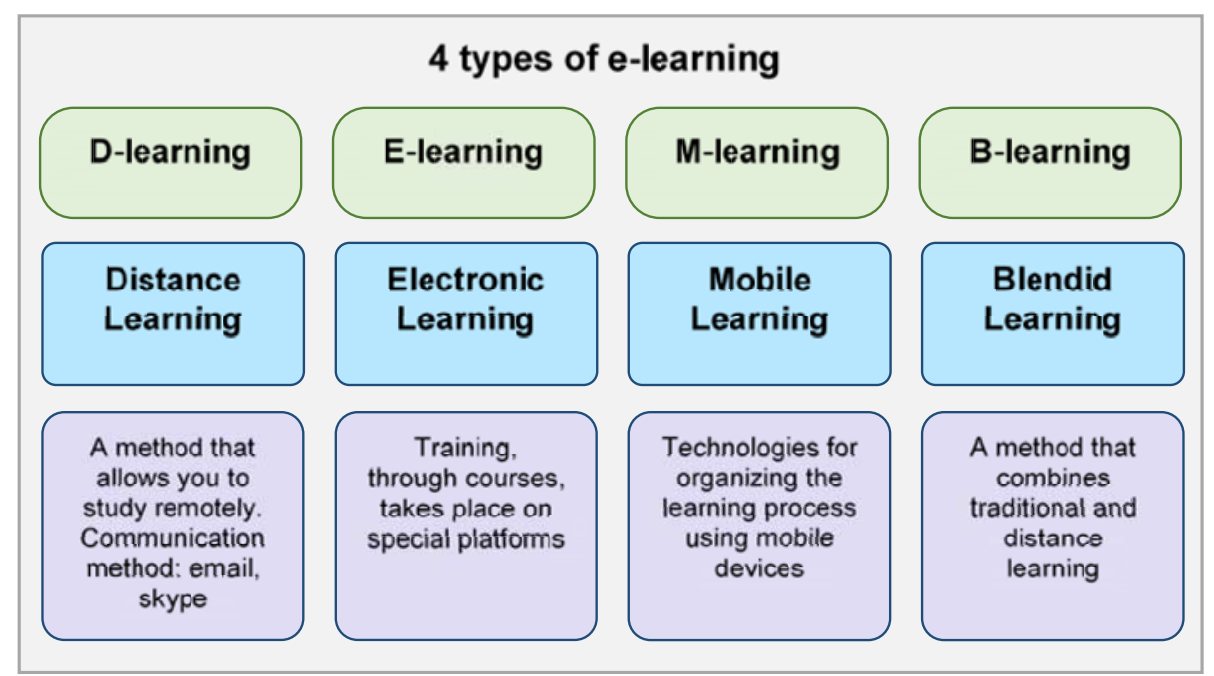

Fig. 1. Types of online learning.

Considering the features of offline and online education, it follows that online education will be more comfortable for people who want to improve their skills in areas of interest to them, as well as combine work, personal life with additional training, without being tied to location.

\section{Materials and Methods}

In many courses, there are currently several paid plans with different functionality, thus each student can choose the amount of feedback from teachers and additional functions. Figure 2 shows a comparative table of the two types of training.

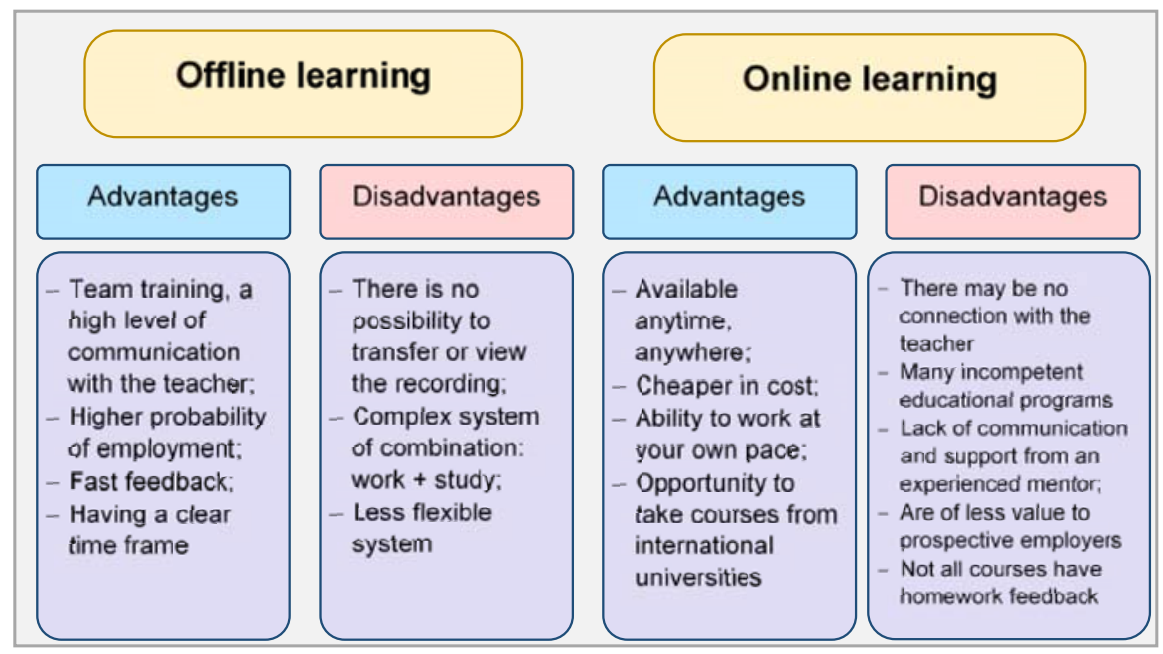

Fig. 2. Comparison of online and offline training. 
Consider the key performance indicators of platforms related to online education over the last period. The total revenue of large participants in online education in the second quarter of 2020 amounted to 6.2 billion rubles, which is $26.5 \%$ more than in the previous quarter and $87 \%$ higher than in the same quarter last year [3,4]. Figure 3 shows the ranking of the largest educational platforms for the 2 nd quarter of 2020 .

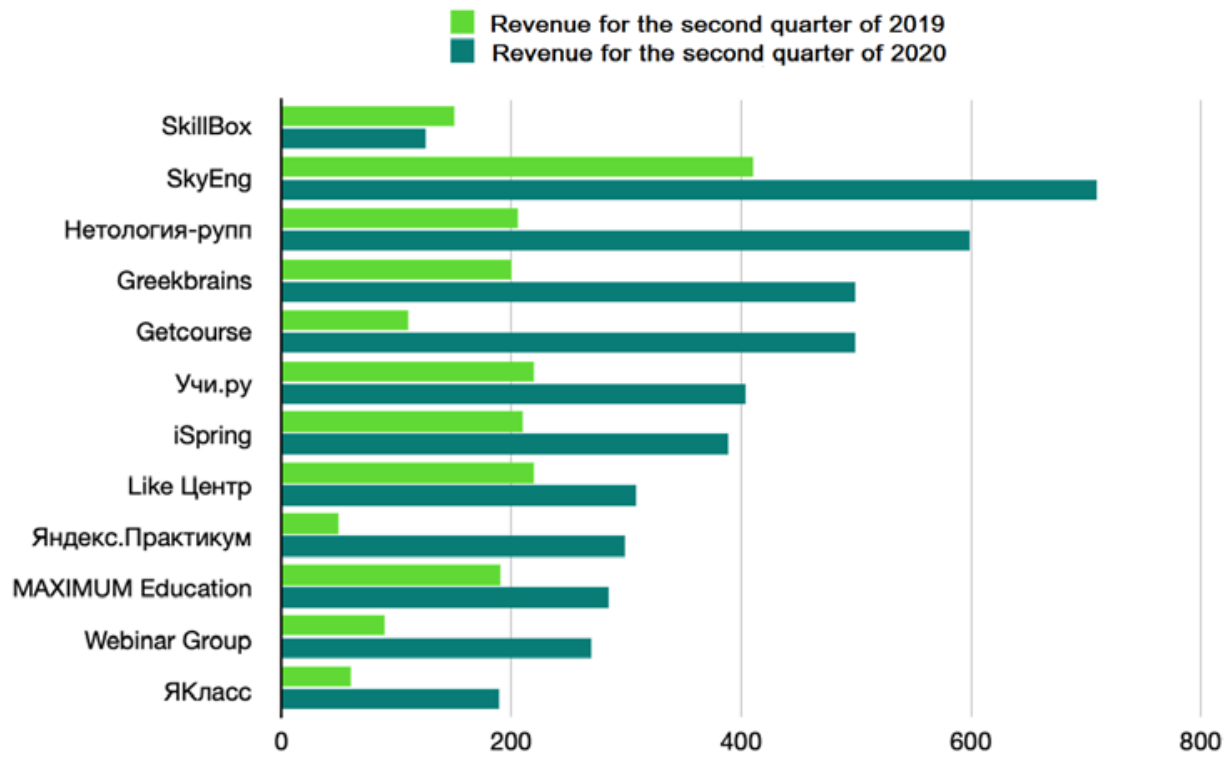

Fig. 3. Rating of large EdTech platforms for the 2nd quarter of 2020 [1].

During the same period, there has been a change in the leader of directions in online education. Prior to that, leading positions in terms of revenue were occupied by large schools of teaching English, but now the online university of modern professions, where programming is the main bias, is in the lead $[5,6]$.

The demand for English courses during the quarantine restrictions remained at the same level, but the need for mastering digital professions has increased several times due to the flexible change in the working field and life prospects. Large investors began to acquire parts of such companies. For example, the Skillbox project has acquired a strong investor Mail.ru Group [7].

The main new and growing target audience for online educational platforms has become school education. With the transition to remote mode, the need arose to use platforms that would generate access to homework, video tutorials and a teacher-friendly interface. Thus, the YaKlass platform reached the maximum gain with an increase of $89.86 \%[8,9]$.

The most massive directions in additional online education for adults are shown in Figure 4. Thus, the largest share in 2019 was concentrated in the field of teaching foreign languages (turnover amounted to 5.3 billion rubles per year). This is followed by the IT industry, which in 2020 has overtaken the teaching of foreign languages from the top. A more detailed segmentation of the online continuing education market is shown in Figure 5.

Consider the main trends in online education that will continue in the near future. More and more attention in Western and European countries is paid to training soft skills (flexible skills) and the inclusion of related cultural disciplines in one of the priority knowledge for employment. The accelerating pace of life and the constant striving for self-realization of people encourage them to pay more and more attention to knowing themselves through the acquisition of appropriate online courses [10]. 


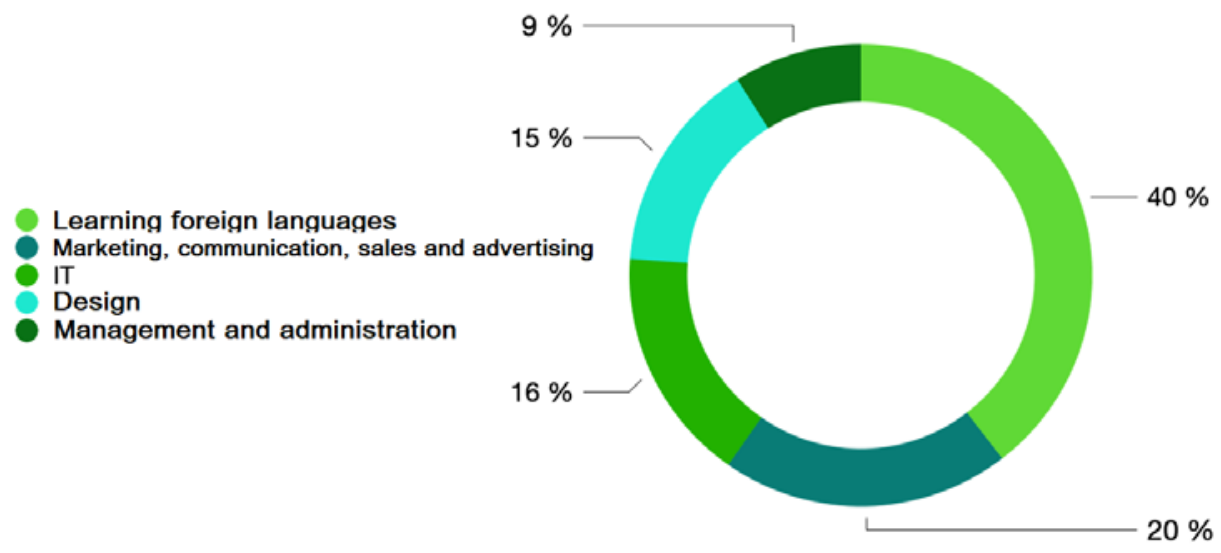

Fig. 4. Segmentation of directions in online education relative to revenue in 2019 [11].

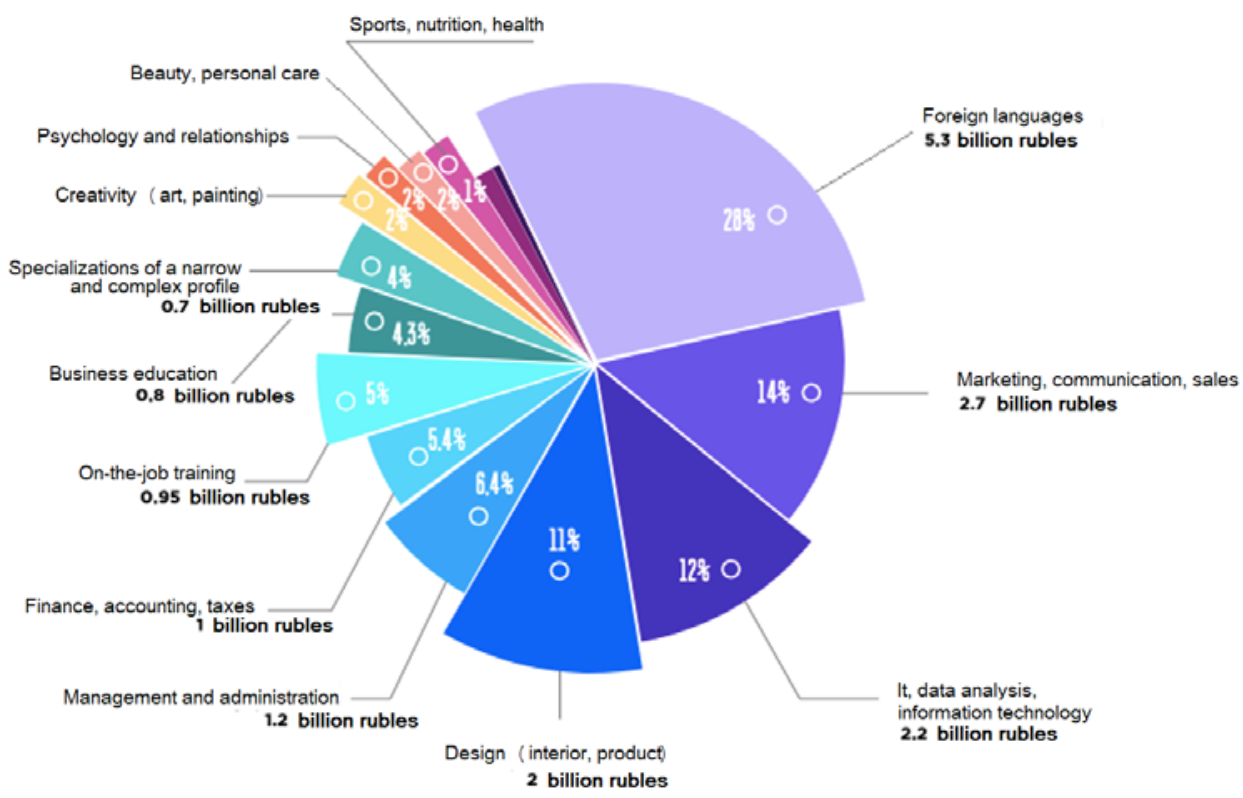

Fig. 5. Segmentation of directions in online education relative to revenue in 2019 [11].

\section{Results and Discussion}

Online education can be an additional source of income and a promising area of activity for large companies not related to the field of education [12]. For example, large online platforms related to the sale and rental of real estate can supplement their sites with additional sections on educational courses related to topics advising in the industry: choosing and purchasing a first apartment, legal aspects for a real estate buyer, buying an apartment in a new building, market specifics $[13,14,15]$. Thus, such courses will not only allow users to independently resolve some issues, but also increase loyalty to the site, thereby convincing users that the company is interested in their success in real estate transactions. 
According to a study by TalentTech, the hobby-learning segment has grown by $19 \%$, that is, there is an increase in interest in areas not related to people's professional activities, for example, personal financial efficiency, art education, applied design skills, motivational education. This also makes it possible to develop this direction for companies with a different profile $[16,17,18]$.

In order to analyze the trend towards the development of online education, let us look at the overall revenue indicators since 2016. As can be seen from Table 1, revenue growth is increasing every year, the maximum jump was in 2020 due to the global lockdown, which greatly increased interest in this area and the development of the industry and allowed entrepreneurs to become more active in this industry.

Table 1. Total revenue of companies in the field of online education in Russia for 2016-2020.

\begin{tabular}{|c|c|c|c|c|c|}
\hline Period & $\mathbf{2 0 1 6}$ & $\mathbf{2 0 1 7}$ & $\mathbf{2 0 1 8}$ & $\mathbf{2 0 1 9}$ & $\mathbf{2 0 2 0}$ \\
\hline $\begin{array}{c}\text { Total revenue of } \\
\text { online education } \\
\text { companies, billion } \\
\text { rubles }\end{array}$ & 20.7 & 26 & 30.3 & 39.5 & 56 \\
\hline
\end{tabular}

Based on the statistics presented above, a correlation-regression model was derived: $y=$ $1.95 \times 2-3.29 x+22.92$ with a correlation equal to 0.9908 , where $\mathrm{x}$ is the period under study, $y$ is the volume of the online education market in Russia (bln. rub). For the education industry, this level of dependence is reliable, and in the coming year, with such a forecast, the industry is expected to increase to 74.6 billion rubles. The prospects for this forecast are realistic, since over the past year, the amount of investment in online education and the quality of the target audience of such a training system have significantly increased. Figure 6 shows the resulting model of the dependence of indicators.

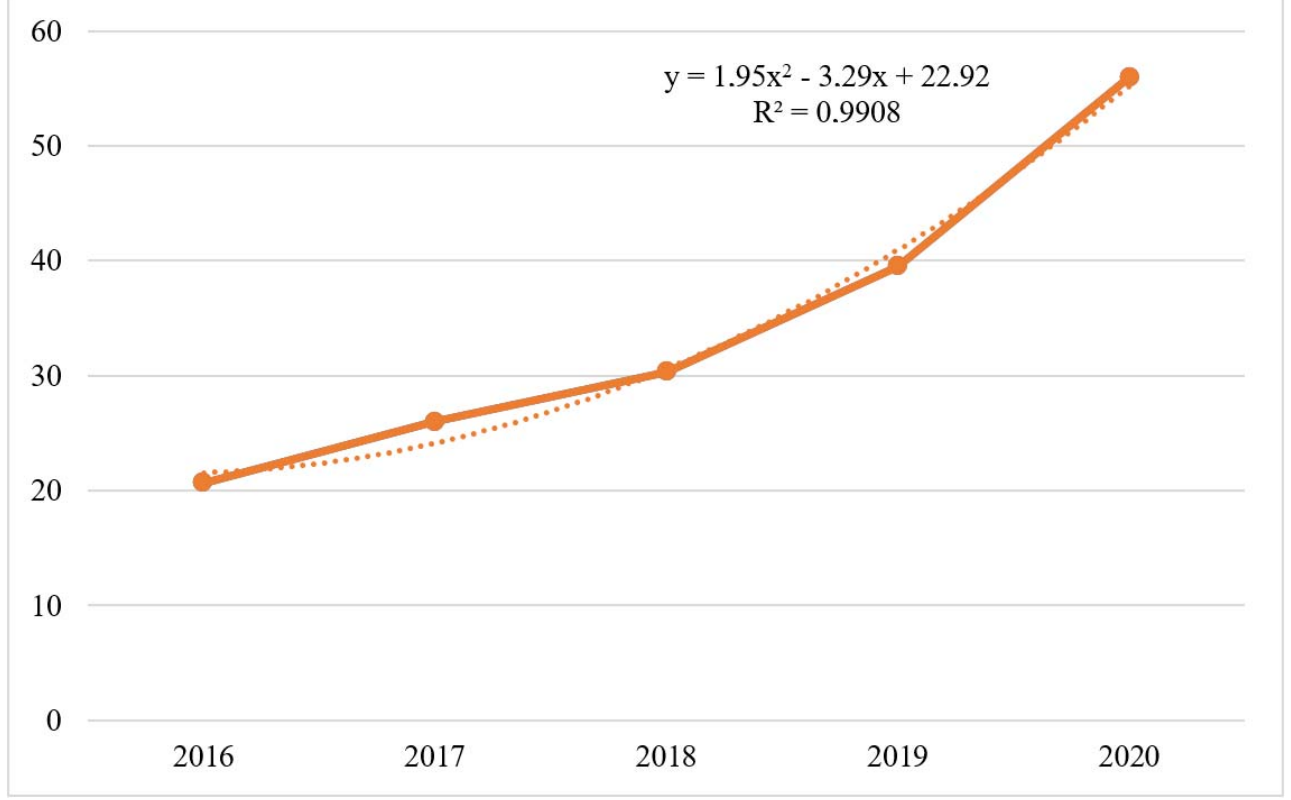

Fig. 5. Volume of the online education market in Russia, 2016-2020 in billion rubles. 


\section{Conclusion}

Over the past five years, venture capital investments in Russia have attracted 70 EdTech projects, while the average deal size did not exceed $\$ 2$ million. The number of companies and platforms that provide significant demand in this area is increasing every year, which has been significantly increased by the coronavirus pandemic. Thus, the Russian EdTech market is consolidating, in which large corporations are becoming the leading power centers. In addition, for many large companies not related to training, the introduction of a separate direction of training can become an additional source of profit.

The situation with the coronavirus pandemic allowed the industry to accelerate in development several times in comparison with the planned values. Many pre-existing platforms related to teaching schoolchildren and students quickly and significantly improved all the features necessary for full-fledged and convenient learning. Video services such as YouTube, Netflix, SchoolTube and others will be even more actively used. Users will create more and more learning content - both holistic materials and individual passages that teachers can add to their curriculum.

When constructing a correlation model, it was possible to identify a clear interconnection of indicators and in the next year, with such a forecast, an increase in the volume of the industry is expected to exceed 70.6 billion rubles. The main developing areas of study: IT specialties, marketing, foreign languages and soft skils.

\section{References}

1. B.S. Klaas, M. Klimchak, M. Semadeni, J.J. Holmes, Journal of Business Venturing 25, 349-360 (2010) https://doi.org/10.1016/j.jbusvent.2008.12.002

2. A.E. Castillo, G.V. Pacheco, L. Hernández-Fernández, E.N. Manotas, J. Silva, $\begin{array}{llll}\text { Procedia Computer Science 160, 567-572 } & \text { (2019) }\end{array}$ https://doi.org/10.1016/j.procs.2019.11.046L

3. M. Prys, J. Krysińska, P. Janaszkiewicz, P. Winiecki, P. Różewski, Procedia Computer Science 126, 1197-1205 (2018) https://doi.org/10.1016/j.procs.2018.08.060

4. P. Gomes, Z. Kuehn, Review of Economic Dynamics 26, 164-179 (2017) https://doi.org/10.1016/j.red.2017.03.004

5. S.B. Holland, Journal of Corporate Finance 46, 374-390 (2017) https://doi.org/10.1016/j.jcorpfin.2017.08.003

6. B. Jacobs, Labour Economics 14, 913-925 https://doi.org/10.1016/j.labeco.2007.06.008

7. O. Pirogova, E. Gorin, V. Plotnikov, E3S Web of Conferences 91, 08021 (2019)

8. V. Plotnikov, O. Pirogova, Key Competencies as an Enterprise Value Management Tool, IBIMA 2018, 1716-1721 (2018)

9. M. Martín-Peña, J. Sánchez-López, E. Díaz-Garrido, Journal of Business \& Industrial Marketing 35(3), 564-574 (2019) https://doi.org/10.1108/JBIM-12-2018-0400

10. E. Fang, W.R. Palmatier, J.-B.E. Steenkamp, Journal of Marketing 72, 1-14 (2008) https://doi.org/10.1509/jmkg.72.5.1

11. M.M. Hasan, Journal of Contemporary Accounting \& Economics 13, 20-36 (2017) https://doi.org/10.1016/j.jcae.2017.01.002

12. K.M. Bakarich, M. Hossain, J. Weintrop, Journal of Contemporary Accounting and Economics 15(1), 69-86 (2019) https://doi.org/10.1016/j.jcae.2018.12.002 
13. O. Pirogova, V. Plotnikov, Z. Popovic, TransSiberia 2019 AISC 1116, 738-747 (2020) https://doi.org/10.1007/978-3-030-37919-3_73

14. A.A. Salisu, I.D. Raheem, U.B. Ndako, Resources Policy 66, 101605 (2020) https://doi.org/10.1016/j.resourpol.2020.101605

15. M. Sevilir, Journal of Financial Intermediationn 19, 483-508 (2010) https://doi.org/10.1016/j.jfi.2009.08.002

16. C. Christiansen, J. Joensen, H. Nielsen, Labour Economics 14, 971-986 (2007) https://doi.org/10.1016/j.labeco.2007.06.001

17. R. Almeida, P. Carneiro, Labour Economics 16, 97-106 (2009) https://doi.org/10.1016/j.labeco.2008.06.002V.

18. B. Carmichael, A. Coën, Finance Research Letters 32, 101172 (2020) https://doi.org/10.1016/j.frl.2019.04.029 